\title{
ABCÊ Bulir: Uma Proposta de Software Educacional para o auxilio no Processo de Alfabetização e Desenvolvimento Cognitivo de Crianças com Síndrome de Down
}

\author{
Michel S. Rodrigues e Zildomar C. Félix \\ Unidade Acadêmica de Serra Talhada (UFRPE - UAST) \\ Universidade Federal Rural de Pernambuco \\ Cep 56.900-000 - Serra Talhada - PE - Brazil \\ \{michel.ufrpe, zildomarf\} @gmail.com
}

\begin{abstract}
Children with Down syndrome (DS) show a relative cognitive deficit, causing some delay in literacy. Considering this context, the aim of this work is to show the characteristics of the cognitive processes of children with DS and propose the development of an educational software with support Natural User Interface, using, for this, is used the device hardware motion detection from Microsoft, called Kinect.
\end{abstract}

Resumo. As crianças com Síndrome de Down (SD) apresentam um relativo déficit cognitivo, ocasionando certo atraso na alfabetização. Considerando este contexto, o objetivo deste trabalho é evidenciar as características do processo cognitivo de crianças com SD, e propor o desenvolvimento de um software educacional com suporte a Interface Natural de Usuário, utilizandose, para isso, o dispositivo de hardware de detecção de movimentos da Microsoft, denominado Kinect.

\section{Introdução}

A Síndrome de Down ou Trissomia 21 é a denominação atribuída a uma alteração genética que ocorre no processo de formação do embrião humano. Estima-se que a cada 1 entre 800 ou 1 entre 1000 neonatos, nasce uma criança com Síndrome de Down (Mustachi, 2007). A Síndrome de Down (SD) acarreta uma série de alterações que afetarão o desenvolvimento cognitivo e corporal da criança, entre elas o comprometimento intelectual. Stray-Gurdersen (2007) em seus estudos enfatiza que "o crescimento e a aprendizagem, em conjunto com fatores psicológicos, culturais e ambientais favoráveis, podem ajudar a reduzir o impacto dessas deficiências".

Contemporaneamente, ter a capacidade de ler é um requisito fundamentalmente básico e necessário para qualquer ser humano para que se permita viver independentemente, sem a intervenção e subsídios de terceiros, bem como exercer sua cidadania e desenvolver-se intelectualmente. Sendo assim, torna-se imprescindível desenvolver métodos alternativos e ferramentas que permitam auxiliar os professores no processo de alfabetização dessas crianças.

As tecnologias computacionais têm evoluído constantemente e estão presentes em diversos segmentos da sociedade, tais como, comércio, entretenimento e educação. Especificamente, as tecnologias computacionais orientadas a educação são 
desenvolvidas no intuito de auxiliar professores e alunos no processo de ensino e aprendizagem. No entanto, essas tecnologias podem não ser aplicáveis a uma criança com Síndrome de Down, haja vista as especificidades que elas apresentam em seu desenvolvimento global.

O presente artigo está organizado da seguinte forma. Na seção 2 é apresentado o referencial sobre Síndrome de Down, na seção3 mostra a proposta do projeto Abcê Bulir e na seção 4 é apresentada as considerações finais.

\section{Síndrome de Down e o Processo Cognitivo}

A Síndrome de Down (SD) é um distúrbio genético complexo que resulta em consequências danosas ao desenvolvimento global do neonato. Cunningham (2011) declara que a SD consiste em um excedente de cromossomos nas células, isto é, existe um cromossomo extra no par de cromossomos de número 21.

O processo cognitivo de crianças com Síndrome de Down é diferente tomando-se como parâmetro o processo cognitivo de crianças não afetadas pela SD. Buckley e Bird (1994) evidencia que para ajudar crianças com SD a aprender é necessário oferecer a eles mecanismos de aprendizagem adequados envolvendo escola, família e comunidades, as quais precisam unir-se para desenvolver a aprendizagem e o meio onde vivem.

Lima (2009) ressalta que as crianças com Síndrome de Down exprimem dificuldades em assimilar informações através da memória auditiva de curto prazo, gerando assim dificuldades de aprendizagem na forma tradicional de ensino oral e narrativa praticada pela maioria das escolas, no entanto elas apresentam uma característica a ser potencializada que é a memória visual, podendo, desta forma, utilizar essa habilidade para executar atividades e utilizar instrumentos que utilizem efeitos visuais, imagens e mensagens curtas.

Outra dificuldade inerente é manter a atenção em uma atividade, bem como alternar a atenção de uma atividade para outra, consequentemente, essa falta de atenção influencia negativamente no processo de aprendizagem. (Lima, 2010).

Segundo as Diretrizes Curriculares Nacionais da Educação Básica (2013) a Educação Especial é uma modalidade de ensino integrante da educação regular e ela ocorre transversalmente a outras modalidades e etapas do processo educacional. É obrigação dos sistemas de ensino matricular todos os estudantes que apresentem algum tipo de deficiência, transtorno global do desenvolvimento e altas habilidades, competindo às escolas garantir uma educação de qualidade para todos observando as necessidades educacionais específicas destes alunos.

\section{Software Educacional ABCÊ Bulir}

O Projeto Abcê Bulir consiste em um Software Educacional com o propósito de subsidiar o corpo docente no processo de alfabetização de crianças com Síndrome de Down. Ele utilizará para esse proposito uma Interface Natural de Usuário a qual será implementada através do Microsoft Kinect.

Analisando as características do processo cognitivo de crianças com Síndrome de Down, é possível elencar um conjunto de características ou requisitos que um Software 
Educacional para esse público alvo deverá implementar. A tabela 1 apresenta as características ou requisitos que devem ser implementados.

Tabela 1. Características do Processo Cognitivo de Crianças com SD.

\begin{tabular}{|c|l|}
\hline Ordem & Característica \\
\hline 1. & Fornecer atividades que exijam pouco da criança. \\
\hline 2. & Fornecer poucas instruções as quais devem ser claras e precisas. \\
\hline 3. & Fornecer repetições de instruções e de execuções de tarefas. \\
\hline 4. & Alternar atividades constantemente, como forma manter a atenção da criança. \\
\hline 5. & Utilizar recursos de áudio e animações em paralelo. \\
\hline 6. & Utilizar mensagens curtas. \\
\hline 7. & Parabenizar a criança quando realizar uma atividade de forma correta. \\
\hline
\end{tabular}

Desta forma, considerando os requisitos elencados na tabela acima, o Software Educacional Abcê Bulir conterá três módulos:

1. Módulo de Apresentação do Alfabeto: Módulo que consiste em apresentar ao discente as letras do alfabeto.

2. Módulo de Formação de Sílabas: Módulo que consiste em apresentar ao discente a formação de sílabas.

3. Módulo de Formação de Palavras: Módulo que consiste em formar pequenas palavras.

O Software poderá ser executado de acordo com as escolhas do docente, isto é, o docente poderá escolher um dos três módulos acima descritos, e nós Módulos de Apresentação do Alfabeto e Formação de Sílabas o docente escolherá se o módulo será executado linearmente ou uma determinada letra ou sílaba, como forma de reforçar o aprendizado. Cada módulo será constituído de fases e cada fase será constituída de duas etapas que são a etapa de Apresentação da Informação e a etapa de Execução de Atividade. A figura 1 apresenta o esboço de um diagrama de classes do projeto.

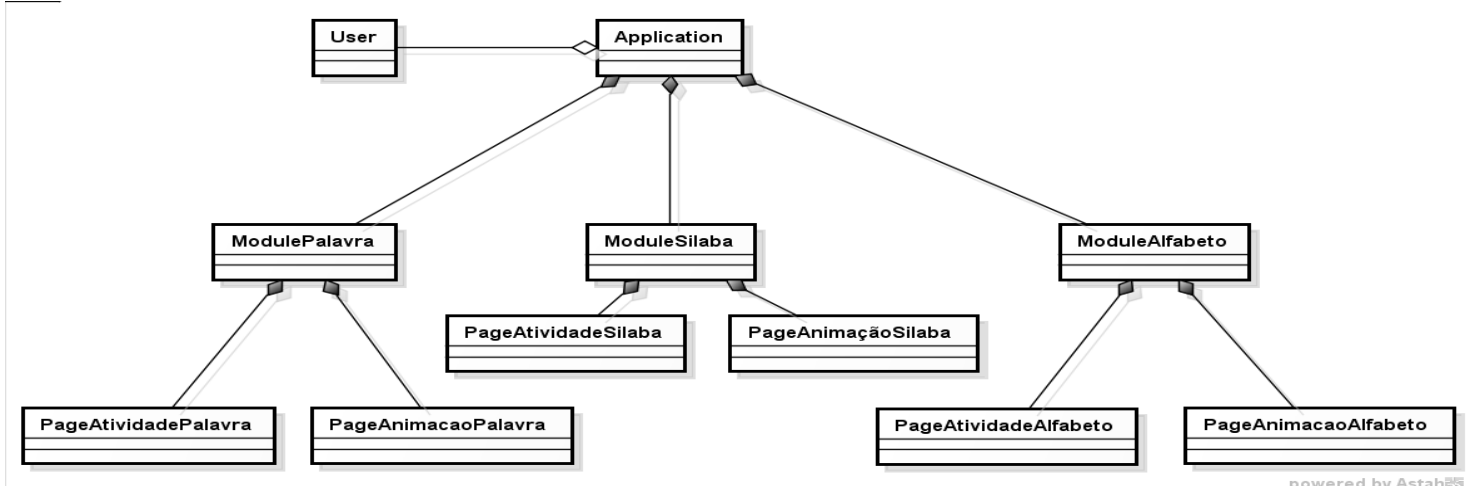

Figura 1 Diagrama de classes do Projeto Abcê Bulir.

No Módulo de Apresentação do Alfabeto a etapa de Apresentação da Informação consiste em apresentar as letras seus respectivos fonemas através de animações, isto é, 
as letras se moverão, ampliarão e reduzirão de tamanho repetidas vezes. Neste mesmo módulo, a etapa Execução de Atividade consiste em o usuário mover com uma das mãos esquerda ou direita objetos virtuais que representarão letras e as encaixar em seus respectivos moldes. Todas as atividades do software terão imagens/cenários com objetos que fazem alusão ao momento pedagógico ao qual estará inserido.

No Módulo de Formação de Sílabas a etapa de Apresentação da Informação consiste em apresentar as sílabas e seus respectivos sons através de animações, isto é, as letras irão mover-se e unir-se e logo após haverá a emissão do som que a representa, essa animação ocorrerá repetidas vezes.

No Módulo de Formação de Palavras a etapa de Apresentação da Informação consiste em apresentar uma imagem de um objeto com seu respectivo nome e logo após através de animações, mostrar a formação da palavra que representa esse objeto juntando as sílabas e novamente mostrando a imagem que a representa. A etapa de Execução de Atividade consiste em o usuário formar a palavra que representa uma imagem que será exibida na tela.

As animações serão repetidas várias vezes no intuito de que as crianças consigam manter a atenção e reter o conhecimento. A atividade de mover os objetos virtuais com uma das mãos para encaixar em seus respectivos moldes pretende trabalhar a lateralidade e a noção espacial da criança, bem como, provavelmente, irá contribuir ainda mias para a retenção da informação. Outro grande potencial deste Software é a possibilidade de contribuir, efetivamente, para uma educação inclusiva, pois, nada impede que crianças sem a Síndrome de Down também utilizem o software.

\subsection{Trabalhos Relacionados}

Esta seção destina-se a descrever os projetos de Software Educacional cuja busca restringe-se a trabalhos escritos em língua portuguesa e que utilizem Interface Natural de Usuário como suporte para auxiliar os docentes no processo de ensino e aprendizagem de crianças com Síndrome de Down. Os trabalhos obtidos foram o MoviLetrando (Fárias et al., 2013) e o Eurotreino (Ana Pinto, 2012).

Farias et al. (2013) utiliza o conceito de Realidade Virtual de Projeção, utilizando apenas uma webcam e um computador convencionais para a execução do jogo. $\mathrm{O}$ jogo constitui-se na captura da imagem do jogador através da webcam, na emissão de sons que representam os objetos virtuais, como por exemplo letras e números e na interação do jogador com esses objetos virtuais através do toque virtual.

Ana Pinto (2012) utiliza o conceito de Interface Natural de Usuário e o jogo consiste em três etapas: (1) exibição e memorização de cédulas e moedas; (2) ordenação dos elementos (cédulas ou moedas) de acordo com o valor monetários; e (3) executar operações financeiras. A interação ocorre em primeira pessoa e o jogador interage com os elementos do jogo através de um ícone com o formato de uma mão.

Considerando os trabalhos descritos, percebe-se uma incipiente pesquisa nessa área, ou seja, poucos Softwares Educacionais com utilização de NUI com ênfase em crianças com SD foi desenvolvido. Percebe-se ainda que características cognitivas elencadas na seção "Síndrome de Down e o Processo Cognitivo", que ambos os trabalhos utilizaram algumas e deixaram de utilizar outras características. Assim, o software educacional 
"Abcê Bulir" reunirá o máximo de características que potencializem o processo de alfabetização de crianças com SD. Portanto, ele utilizará recursos de áudio e animação paralelamente, diferentemente de ambos os trabalhos relacionados que não utilizam este recurso.

\section{Conclusão}

São notórias as dificuldades de aprendizagem de crianças com Síndrome de Down, desta forma, esse perfil de crianças exige uma abordagem de ensino e aprendizagem diferenciada. O Software Educacional e os Jogos Sérios estão cada vez mais presentes no contexto educacional e sendo utilizados como formas alternativas de educação, no entanto, as crianças com Síndrome de Down apresentam características cognitivas próprias que devem ser observadas e que por vezes não estão presentes nessas ferramentas.

O Software Educacional Abcê Bulir surge como diferencial para o processo de ensino e aprendizagem de crianças com esse perfil, porque, congrega em seu bojo funcional diversas características do processo cognitivo desse perfil de crianças, como também, utiliza um novo conceito de IHM (Interação Homem-Máquina), denominado Interface Natural de Usuário, a qual, provavelmente, poderá ser um diferencial no que se refere ao déficit de atenção que esse perfil de crianças apresenta como característica do seu processo cognitivo.

\section{Referências}

PINTO, A. C. S. Desenvolvimento de Um Jogo para jovens/adultos portadores de Síndrome de Down. 2013. 119 f. Tese (Mestrado em Multimídia) - Universidade do Porto, Porto. 2013.

Buckley, S. J.; BIRD, G. Meeting the educational needs of children with Down Syndrome. Down Syndrome News Update, Portsmouth, 1999 v. 1, n. 4, p. 159-174.

Cunningham, Cliff. Down Syndrome: An Introduction for Parents and Carers. $3^{\mathrm{a}}$ ed. London: Souvenir Press, 2011. 480p.

Farias, E. H., Hounsell, M. S., Blume, L. B., Ott, F. R., Cordovil, F. V. P. MoviLetrando: Jogo de Movimentos para Alfabetizar Crianças com Down. In: Congresso Brasileiro de Informática na Educação, 2., 2013, São Paulo-SP.

Lima, R. P. O Uso de Software Educacional como Mediador Instrumental na Aprendizagem de Crianças com Síndrome de Down. 2009. 94 f. Mestrado em Desenvolvimento Regional, Universidade Federal do Amapá, Macapá. 2009.

Lima, J. B. F. Síndrome de down: desafios e potencialidades aprendendo para e sobre o down: In: Kopzinski, S. D. (Org.). Percursos Psicopedagógicos: entre o saber e o fazer. Rio Grande do Sul: Editora Feevale, 2010. p. 65-72.

Mustachi, Z. Síndrome de Down - Caracterização Geral. In: Sociedade Brasileira de Clinica Médica. Diagnostico e Tratamento. Volume 3. Editora Manole Ltda., 2007 Cap. 6, p. 239-258.

Stray-Gundersen, K. Crianças com Síndrome de Down: Guia para pais e Educadores. $2^{\text {a }}$ ed. Porto Alegre: Artmed, 2007. 280 p. 